Gut, 1971, 12, 804-810

\title{
Intestinal lymphoma and sprue: A systematic approach $^{1}$
}

\author{
WERNER DUTZ, SHAHLA ASVADI, SHAHNAZ SADRI, AND \\ ELFRIEDE KOHOUT
}

From the Department of Pathology, Pahlavi University Medical School, Shiraz, Iran

SUMmARY Intestinal lymphoma is frequently associated with sprue-like bowel patterns. A standardized approach to the problem is suggested.

Intestinal lymphoma has been subdivided into four groups, depending on the extent of involvement of the anatomical region. Only cases with specific lesions are accepted as primary lymphoma.

The villous pattern in 179 cases at necropsy with suitably preserved mucosa was determined to form a normal baseline for comparison with the uninvolved portions of the lymphomatous small bowel. Only $15 \%$ of all small bowel of this random material of children more than 1 year old and adults showed a flattened mucosa.

The non-lymphomatous mucosa of 20 cases with definitely primary intestinal reticulum or lymphosarcoma showed severe sprue-like atrophy in $18(90 \%)$. Two cases of intestinal Hodgkin's disease and four cases of gastric lymphoma were associated with regular mucosal patterns.

It is concluded that sprue-like villous atrophy of the small bowel is definitely a triggering factor for the development of primary intestinal reticulum cell or lymphosarcoma. A hypothesis for the possible aetiological relationship of these two conditions is discussed.

The association of lymphoma with sprue-like malabsorption has been well recognized. Some authors believed that this might be due to mechanical obstruction of the lymphatics by tumour (Salvesen, 1948; Bjerkelund, 1950; Bank, Fisher, Marks, and Groll 1967) or motility disturbances due to the lymphomatous infiltration of the bowel wall inhibiting peristalsis either by the mass of the lymphomatous tissue or the infiltration of the myenteric plexus (Fairley and Mackie, 1937; Bickel and Rutishauser, 1942). It has been suggested recently that sprue-like atrophy of the bowel mucosa may be a precursor of lymphoma (Sleisenger, Almy, and Barr, 1953; Culver, Benson, Strauss, and Jones, 1959; Gough, Reid, and Naish, 1962; Barrett, 1964; Eidelman, Parkins, and Rubin, 1966; Austad, Cornes, Gough, McCarthy, and Read, 1967; Huntington, Larwood, Armstrong, Palitz, Hance, and Moses, 1970) if not also favouring the development of several other types of malignant change of the upper gastrointestinal tract (Dawson, Cornes, and Morson, 1961; Hermans, Huizenga, Hoffman,

${ }^{1}$ This study was supported by Cento and Pahlavi University research funds

Received for publication 6 July 1971.
Brown, and Markowitz, 1966; Harris, Cooke, Thompson, and Waterhouse, 1967).

A clarification of the aetiological relationship of intestinal lymphoma and sprue-like atrophy of the bowel mucosa with or without clinical signs and symptoms of malabsorption can only be achieved by the study of a large series. Although this disease pattern is relatively frequent amongst the poorer classes of the Middle East (Ramot, Shahin, and Bubis, 1965; Eidelman et al, 1966; Gédéon, 1970; Nasr, Haghighi, Bakhshandeh, and Haghshenas, 1970) none of the series is well enough standardized to permit comparison nor large enough for valid conclusions. Only the cooperative effort of many in an area of high incidence of the condition will permit final clarification of the relationship of sprue to primary intestinal lymphoma.

The purpose of this study was the development of a standardized approach to intestinal lymphoma. This necessitates staging of the lymphoma to separate primary cases from those in which the bowel may be infiltrated by a lesion starting in another site. Classification according to type of lymphoma may reveal the preferential association of one or the other with malabsorption. 
Equally important is standardization of the approach to malabsorption. Biochemical tests performed in different laboratories are subject to too many variables to be of help. Villous patterns are more easily classified and less subject to variations in interpretation or technique (Loehry and Creamer, 1966). Anatomical evidence of abnormal villous patterns should be found in portions of the bowel uninvolved by lymphoma, if sprue is indeed its precursor. The examination of multiple sections of the uninvolved bowel and classification of the villous patterns is, however, only meaningful if the results can be compared with the usual pattern for a specific population. The knowledge of the usual bowel pattern in health and disease in a large series of necropsies was therefore a precondition for this study.

\section{Materials and Methods}

All diagnoses of necropsies and biopsies examined at Pahlavi University Pathology Department were coded with the SNOP code, punched on IBM cards, and screened for lymphoma. Seventy-seven cases of lymphoma involving the intestinal tract were observed from 1960 to 1969 . Sufficient material and information was available in 65 cases. Thirty-nine of these permitted also the evaluation of the villous pattern in the uninvolved portions of the bowel undistorted by autolytic changes.

The lymphomas were subdivided in four groups. In the first stage only the bowel mucosa or bowel wall were involved. There was no lymph node lesion on macroscopic or microscopic examination. Only necropsy cases were admitted to this group. Stage II concerned all those cases in which the intestine and a few focal lymph nodes showed lymphoma but where no large lymph node masses appeared in the mesentery. Stage III contained all cases in which there was no generalized lymphomatous spread but massive bowel and mesenteric lymph node involvement. Although in some cases seen at surgery a discrete spread to other organs could not be excluded, most are probably intestinal in origin. Stage IV pertains to all cases with systematic spread. Some of these lymphomas may have originated in the intestine, others in other organs or lymph nodes, involving the bowel only secondarily. All cases in group IV cannot therefore be considered as primary lymphomas. Figures 1-4 illustrate our four stages.

The cases were histologically classified as reticulum cell sarcoma, Hodgkin's disease, and lymphocytic and lymphoblastic lymphosarcoma. Lymphocytic and lymphoblastic types are recorded together as lymphosarcoma since no difference in biological behaviour could be detected.
In Shiraz necropsies are performed soon after death for various reasons and are usually finished four to six hours after death, or earlier if the death occurs during the day. Excellent refrigeration for bodies is available. Specimens from the duodenum, jejunum, and ileum were examined with the stereomicroscope and histological sections by two independent observers without knowledge of the disease or age of the patient. The results showed excellent agreement between the examiners and the stereoscopic and microscopic patterns. Out of 500 examined cases, 176 showed sufficient preservation to permit analysis of the mucosal pattern. Fingershaped villous pattern was classified as type 1 , leaves as type 2 , crests as type 3 , convolutions as type 4, and flattening in a sprue-like fashion as type 5 . The uninvolved mucosa in the lymphoma patients was evaluated by the same observers in the same fashion. All results were decoded after classification and arranged according to primary disease.

\section{Results}

The relative frequency of lymphomas in Shiraz is summarized in Table I. About one-fifth of all

\begin{tabular}{|c|c|}
\hline $\begin{array}{l}\text { Total no. of neoplasms } \\
\text { Total no. of lymphomas } \\
\text { No. in males } \\
\text { Percentage of male neoplasms } \\
\text { No. in females } \\
\text { Percentage of female neoplasms } \\
\text { Cases of gastrointestinal lymphoma } \\
\text { Percentage of total no. of lymphomas }\end{array}$ & $\begin{array}{rr}3,006 & \\
364 & (11.98 \%) \\
242 & \\
& 18 \cdot 58 \% \\
122 & \\
77 & 7.68 \% \\
& 21.25 \%\end{array}$ \\
\hline
\end{tabular}

Table I Lymphoma frequency in biopsy and necropsy material 1960-1969

lymphomas involve the gastrointestinal tract. The villous structure of the bowel in 176 necropsies of non-lymphomatous cases appears in Table II, which

\begin{tabular}{lrlllll}
\hline & \multicolumn{7}{c}{ Type of Mucosal Pattern } \\
\cline { 2 - 7 } & 1 & 2 & 3 & 4 & 5 & 4 and 5(\%) \\
\hline Duodenum & 9 & 58 & 86 & 21 & 2 & 13.06 \\
Jejunum & 21 & 78 & 52 & 21 & 4 & 14.20 \\
Ileum & 89 & 45 & 17 & 17 & 5 & 12.71 \\
\hline
\end{tabular}

Table II Bowel patterns in 176 cases without lymphoma in Shiraz

reveals a considerable shift from the ideally normal finger-shaped villous pattern towards leaf-like and crest-like appearances. These patterns are practically never associated with symptoms of disease and must therefore be considered usual for the region. There 
was no particular preference for age groups or particular diseases after the first year of life. An incidence of more than $15 \%$ of types 4 and 5 , that is, convoluted and flat mucosal patterns, must be considered abnormal for the Shiraz area.

The type and extent of the lymphoma and the associated villous pattern in those cases in which material was available is recorded in Table III. The

\begin{tabular}{lcccc}
\hline Stage & \multicolumn{2}{c}{ Bowel Pattern } & \multicolumn{2}{c}{ Total No. of Cases } \\
\cline { 2 - 4 } & $1-3$ & $4-5$ & \multicolumn{2}{c}{ Unknown } \\
\hline I & 1 & 1 & 0 & 2 \\
II & 1 & 9 & 2 & 12 \\
III & 0 & 8 & 3 & 11 \\
IV & 6 & 9 & 19 & 34 \\
Stomach & 4 & 0 & 2 & 6 \\
Total & 12 & 27 & 26 & 65 \\
\hline
\end{tabular}

Table III Bowel pattern in lymphoma in Shiraz

$10=$ no bowel available, $1=$ finger-like villi, $2=$ leaf-like villi, $3=$ crest-like villi, $4=$ convoluted villi, $5=$ flat mucosa (sprue pattern).

cases are arranged in sequence of age at diagnosis by surgery or necropsy. The average age of the 27 cases of reticulum-cell sarcoma and the two cases of Hodgkin's disease is 33 years, and of the 30 cases of lymphocytic and lymphoblastic lymphosarcoma 25.6 years. The ratio of male to female cases in lymphosarcoma is $21: 9$, while reticulum-cell sarcoma shows an equal sex distribution.

Practically all cases showed multifocal involvement of the intestinal tract. Scattering of submucosal lymphoma was seen even in stages I-II. Grossly all different forms of lymphoma described by Marshak, Wolf, and Eliasoph (1961), by Schlaeger (1967), and Balikian, Nassar, Shammaá, and Shahid (1969) were present: stenosing, diffusely infiltrating, with aneurysmal dilatation, perforated, with submucosal infiltration and roughening of the mucosal pattern, multiple nodular, ulcerative, exophytic, and endophytic. The intestinal mucosal pattern of the uninvolved bowel was unrelated to the macroscopic form of the lymphoma.

Table III summarizes the bowel mucosal patterns found in the individual stages of lymphoma. Twenty cases of primary lymphoma (stages I-IV) could be completely analysed. Ninety per cent (18 cases) revealed sprue-like atrophy of the mucosa (pattern 4-5). The findings in stage IV are more equivocal, showing six cases of normal mucosa and nine with flattening. Some of the stage IV lymphomas probably started in other organs and are therefore not aetiologically related to changes in the bowel mucosa. Since it is impossible to separate clearly the primary and secondary category of intestinal lymphoma at this stage of the disease by morphological methods, this finding must be treated with caution. Three of the normal mucosal patterns in stage IV occurred in advanced lymphosarcoma of the bowel in patients more than 30 years old, one only in a reticulum cell sarcoma. Both cases of Hodgkin's disease (stage IV) showed normal mucosal patterns.

Intestinal mucosa was available for study in four out of six cases of gastric lymphoma (three cases of lymphosarcoma and three of reticulum cell sarcoma). All specimens showed normal finger-like bowel patterns, indicating that sprue is not related to gastric lymphoma.

Clinical data were not particularly helpful. The patients are poor historians and laboratory tests for malabsorption were available in a few cases only. As well as the mucosal patterns already mentioned only two cases of stage IV lymphoma, in which no bowel mucosa was available for study, showed definite histological evidence of sprue. Conversely, patients with definite mucosal aberrations (type 4 and 5) did not always complain of diarrhoea or malabsorption. Four cases of stage IV lymphoma and one each of stages I and II fall in this latter category. It should be noted that the normal mucosal patterns are more frequent in older patients with advanced intestinal lymphoma and were not seen below the age of 30 .

\section{Discussion}

Reliable figures for the incidence of neoplastic disease do not exist in the Middle East. Despite numerous sources of error there is, however, a peculiar agreement in the anecdotal incidence figures from various sources, once sufficient case numbers are observed. Azar (1962) found in the material collected at the American University of Beirout the same frequency of lymphomas $(11.9 \%)$ as we observed in Shiraz (Barekat, Saidi, and Dutz, 1971). It appears that lymphoma is more frequent in the Middle East than in Europe or North America (Ullmann and Abeshouse, 1932; Gall and Mallory, 1942; Marcuse and Stout, 1950; Rosenberg, Diamond, Jaslowitz, and Craver, 1961; Azar, 1962; Habibi, 1966; Barekat, Saidi, and Dutz, 1971) and that intestinal lymphoma accounts for a significant part of this increase (Azar, 1962; Ramot, Shahin, and Bubis, 1965; Eidelman et al, 1966; Habibi, 1966; Gédéon, 1970; Nasr et al, 1970; Barekat et al, 1971).

The association of gluten-dependent as well as socalled tropical sprue with intestinal lymphoma was mentioned in the medical literature during the last few decades. Most authors did not establish a rela- 
tionship between these two conditions (Lehmkuhl, 1927; Golden, 1936; Fairley and Mackie, 1937; Bickel and Rutishauser, 1942; Fritszche, 1943; Adlersberg and Schein, 1947; Salvesen, 1948; Singleton and Moore, 1949; Bjerkelund, 1950; Rechnitzer, 1953; Skrimshire, 1955; Upshaw and Pollard, 1957; French, Hawkins, and Smith, 1957; Girdwood, 1961 ; Scudamore, 1961 ; Eakins, Fulton, and Hadden, 1964; Benson, Kowlessar, and Sleisenger, 1964; Kent, 1964; Banks et al, 1967; Shreeve, Horrocks, and Mainwaring, 1968). Sleisenger and his coworkers (1953) suggested that sprue may be a factor favouring the development of lymphoma primarily in the bowel. Many reports linking the two conditions have appeared since (Culver et al, 1959; Gough et al, 1962; Barrett, 1964; Eidelman et al, 1966; Austad et al, 1967; Huntington et al, 1970; Nasr et al, 1970).

Many authors mentioned the prolonged latent period between the onset of sprue and the development of lymphoma, which in one case followed 60 years after the first bout of infantile diarrhoea (Scudamore, 1961; Charache, 1956; Kent, 1964; Austad et al, 1967; Shreeve et al, 1968). The frequency of lymphoma increases with the duration of sprue symptoms (Tonkin, 1963). Several cases of gradual transition of mesenteric lymph node lesions from reticulum cell hyperplasia to lymphoma are recorded (Massachusetts General Hospital, 1957; Salera, Coppolino, Cannata, and Serafini, 1960; Whitehead, 1968). Some of these were associated with dysgammaglobulinaemia (Hermans et al, 1966). The average latent period from the onset of sprue to the development of lymphoma is 21 years according to Harris et al (1961), while carcinomas occur after an average period of 38.5 years of sprue (Dawson et al, 1961; Hermans et al, 1966).

Our cases confirm and substantiate the aetiological association of chronic sprue and primary intestinal lymphoma. The average age of 25 to 33 years of our patients points to an onset of sprue in early infancy. Severe intestinal infections leading to subsequent sprue in infants are well known in the developing regions of the world (Wethered, 1891; Thin, 1890; Siegmund, 1929; Mackie and Fairley, 1929; Keele and Pound, 1946; Klipstein and Falaiye, 1969; Lindenbaum, Kent, and Sprinz, 1966; Jinich, Rojas, Webb, and Kelsey, 1968) and were extremely frequent in central Europe before the turn of the century (Siegmund, 1929).

Sprue-like atrophy of the bowel mucosa occurs in Shiraz in those infants suffering repeated intestinal infections before the sixth month of life due to insufficient breast feeding and the addition of ill prepared and incompletely sterilized formulas to the diet (Creamer, Dutz, and Post, 1970; Dutz, Sadri, Kohout, Post, and Bandarizadeh, 1970). Some recover only incompletely and never grow to optimal size (Ronaghy, Kohout, and Hadidi, 1970). The intestinal atrophy is associated with immune deficiency (Dutz et al, 1970) and on necropsy with marked thymic atrophy. There must be mild forms of this disorder, in which a moderate thymic atrophy is associated with clinically undetectable immunodeficiency.

Lymphoreticular neoplasms occur significantly more often in patients with immunodeficiency diseases, as, for instance, Swiss type agammaglobulinaemia, Bruton's disease, ataxia teleangiectatica, and the Wiscott-Aldrich syndrome (Wall and Saslaw, 1955; Page, Hansen, and Good, 1963; Peterson, Cooper, and Good, 1965; ten Bensel, Stadlan, and Krivit, 1966; Goldman, Haggard, McFadden, Ritzmann, Houston, Bratcher, Weiss, Box, and Szekrenyes, 1967; Bierman, 1968) which in turn are associated with sprue and intestinal atrophy (Sanford, Favour, and Tribeman, 1954; Rosecan, Trobaugh, and Danforth, 1955; Wall and Saslaw, 1955). The increased incidence of Giardia lamblia infection in these cases is probably related to a reduced local immunity rather than being the cause of the sprue (McGrath, O'Farrell, and Boland, 1940; Hermans et al, 1966).

Burnet (1964) suggested that the increased incidence of malignant diseases in early childhood is related to entry of the causative agent in the perinatal period of immunological inadequacy in which recognition of tumour-inducing agents and neoplastic cells is reduced, while the increasing frequency of malignant disease with advancing age is due to the progressive loss of the host's ability to initiate new immunological reactions.

Burkitt's lymphoma is an excellent example of a childhood neoplasm. It occurs in precisely defined geographical areas in tropical Africa and New Guinea (O'Connor, 1963; Dalldorf, 1962) which are characterized by holoendemic malaria with an infantile mortality rate of 12.5 per 1,000 (Dalldorf, 1962; Harris, 1964; Burkitt and Wright, 1970). The aetiological relationship is supported by the reduced incidence of Burkitt's lymphoma in glucose6-phosphate-deficient and sickle-cell anaemic infants. (Dalldorf, Linsell, Barnhart, and Martyn, 1964; Luzzatto, Usanga, and Reddy, 1969). Necropsies on children and infants with Burkitt's lymphoma showed thymic atrophy and excessive amounts of malaria pigment in the spleen (Burkitt and Wright, 1970). It seems that the heavy and early malaria infection leads to thymic atrophy with reduction in the migration of thymic-dependent lymphocytes into the follicles of the lymph nodes as well as a 
constant stimulation of the reticuloendothelial portion of the lymph node, which leads to the development of lymphoma in the cephalic portion of the bursal lymph node system.

Considering the available direct and indirect evidence we suggest the following hypothesis for the development of intestinal lymphoma: severe infective stress in early infancy leads to sprue-like atrophy of the bowel mucosa, thymic atrophy, and various degrees of thymic-dependent immune deficiency. Most infants recover completely, few die with intercurrent infection or marasmus. Some remain with various degrees of blunting of the bowel villi, moderate to mild thymic atrophy, and clinically inapparent immune deficiency, which possibly may be related to an inability to recognize and destroy cell mutants. Virus is more active in immunedeficient animals and tumour viruses may penetrate during the period of early infancy. Chronic infection of the intestine results in reticular hyperplasia of the mesenteric nodes. These factors alone or together may lead to lymphoma of the intestine or mesenteric nodes.

The severe infantile intestinal infection cannot be the sole cause of the lymphoma, since intestinal lymphoma occurs also without being associated with sprue-like atrophy of the mucosa. It most probably is, however, the localizing factor, explaining the high incidence of intestinal lymphoma amongst the poorer population of the Middle East and at an appreciably younger age than elsewhere.

\section{References}

Adlersberg, D., and Schein, J. (1947). Clinical and pathologic studies in sprue. J. Amer. med. Ass., 134, 1459-1467.

Austad, W. I., Cornes, J. I., Gough, K. R., McCarthy, C. F., and Read, A. E. (1967). Steatorrhea and malignant lymphoma: the relationship of malignant tumors of lymphoid tissue and celiac disease. Amer. J. dig. Dis., 12, 475-490.

Azar, H. A. (1962). Cancer in Lebanon and the Near East. Cancer (Philad.), 15, 66-78.

Balikian, J. B., Nassar, N. T., Shammaá, M. H., and Shahid, M. J. (1969). Primary lymphomas of the small intestine including the duodenum. Amer. J. Roentgenol., 107, 131-141.

Banks, S., Fisher, G., Marks, I. N., and Groll, A. (1967). The lymphatics of the intestinal mucosa. Amer. J. dig. Dis., 12, 619-632.

Barekat, A. A., Saidi, F., and Dutz, W. (1971). Cancer survey in South Iran with special reference to gastrointestinal neoplasms. Int. J. Cancer, 7, 753-363.

Barrett, G. M. (1964). Coeliac disease and malignant change. Lancet, $1,723$.

Benson, G. D., Kowlessar, O. D., and Sleisenger, M. H. (1964). Adult celiacdisease with emphasis upon response to the glutenfree diet. Medicine (Baltimore), 43, 1-40.

ten Bensel, R. W., Stadlan, E. M., and Krivit, W. (1966). The development of malignancy in the course of the Aldrich syndrome. Pediatrics, 68, 761-767.

Bickel, G., and Rutishauser, E. (1942). Syndrome de sprue symptomatique d'une lymphogranulomatose de l'intestin et des ganglions mesenteriques. Helv. med. Acta, 9, 697-719.

Bierman, S. M. (1968). The role of immunologic aberrations in the pathogenesis of lymphoma. Arch. Derm., 97, 699-711.

Bjerkelund, C. J. (1950). Symptomatic sprue. Acta med. scand., 137, 130-149.
Burkitt, D. P., and Wright, D. H. (1970). Burkitt's Lymphoma. Livingstone, Edinburgh and London.

Burnet, M. (1964). Immunologic factors in the process of carcinogenesis. Brit. med. Bull., 20, 154-158.

Charache, H. (1956). Lymphosarcoma in infancy and childhood. Including a case of 22 years survival. Amer. J. Roentgenol., 76, 594-598.

Creamer, B., Dutz, W., and Post, C. (1970). Small-intestinal lesion of chronic diarrhoea and marasmus in Iran. Lancet, 1, 18-20.

Culver, P. J., Benson, J. A., Jr., Strauss, E., and Jones, C. M. (1959). Some observations on the malabsorption syndrome, based on the use of absorption tests and biopsy of the small intestine. Gastroenterology, 36, 459-466.

Dalldorf, G. (1962). Lymphomas of African children with different forms or environment influences. J. Amer. med. Ass., 181, 1026-1028.

Dalldorf, G., Linsell, C. A., Barnhart, F. E., and Martyn, R. (1964). An epidemiologic approach to the lymphomas of African children and Burkitt's sarcoma of the jaws. Perspect. Biol. Med., 7, 435-449.

Dawson, I. M. P., Cornes, J. S., and Morson, B. C. (1961). Primary malignant lymphoid tumors of the intestinal tract. Report of 37 cases with a study of factors influencing prognosis. Brit. J. Surg., 49, 80-89.

Dutz, W., Sadri, S., Kohout, E., Post, C., and Bandarizadeh, B. (1970). Bowel mucosal patterns and immunoglobulins in 100 infants from birth to one year of age. Pahlavi med. J., 1, 234243.

Eakins, D., Fulton, T., and Hadden, D. R. (1964). Reticulum-cell sarcoma of the small bowel and steatorrhoea. Gut, 5, 315-323.

Eidelman, S., Parkins, R. A., and Rubin, C. E. (1966). Abdominal lymphoma presenting as malabsorption: a clinico-pathologic study of nine cases in Israel and a review of the literature. Medicine (Baltimore), 45, 111-137.

Fairley, N. H., and Mackie, F. P. (1937). The clinical and biochemical syndrome in lymphadenoma and allied diseases involving the mesenteric lymph glands. Brit. med. J., 1, 375-380.

French, J. M., Hawkins, C. F., and Smith, N. (1957). The effect of a wheat-gluten-free diet in adult idiopathic steatorrhoea. Quart. J. Med., 26, 481-499.

Fritzsche, R. (1943). Syndrom von symptomatischer Sprue bei Lymphosarkomatose des Dünndarms und der mesenterialen Lymphdrüsen. Schweiz. med. Wschr., 73, 442.

Gall, E., and Mallory, T. B. (1942). Malignant lymphoma. Amer. J. Path., 38, 381-415.

Gédéon, E. M. (1970). Primary malignant lymphomas of the digestive tract.J. méd. liban., 23, 1-10.

Girdwood, R. H., Delamore, I. W., and Williams, A. W. (1961). Jejunal biopsy in malabsorptive disorders of the adult. Brit. med. J., 1, 319-323.

Golden, R. (1936). The small intestine and diarrhoea. Amer. J. Roentgenol., 36, 892-901.

Goldman, A., Haggard, M. E., McFadden, J., Ritzmann, S. E. Houston, E.W., Bratcher, R.L.,Weiss, K. G., Box, E. M., and Szekrenyes, J. W. (1967). Thymic alymphoplasia, lymphoma and dysgammaglobulinemia. Pediatrics, 39, 348-362.

Gough, K. R., Read, A. E., and Naish, J. M. (1962). Intestinal reticulosis as complication of idiopathic steatorrhoea. Gut, 3, 232239.

Habibi, A. (1966). Cancer in Iran. A Survey af 28,000 Cases Diagnosed by Histological Examination. Monograph, University of Tehran.

Harris, O. D., Cooke, W. T., Thompson, H., and Waterhouse, J. A. H. (1967). Malignancy in adult coeliac disease and idiopathic steatorrhoea. Amer. J. Med., 42, 899-912.

Harris, R. J. C. (1964). Aetiology of central African lymphomata. Brit. med. Bull., 20, 149-153.

Hermans, P. E., Huizenga, K. A., Hoffman, H.N., II, Brown, A. L., Jr., and Markowitz, H. (1966). Dysgammaglobulinemia associated with nodular lymphoid hyperplasia of the small intestine. Amer. J. Med., 40, 78-89.

Huntington, R. W., Jr., Larwood, T. E., Armstrong, F., Palitz, S., Hance, D., and Moses, I. (1970). Chronic malabsorption (Steatorrhea, nontropical sprue) in an adolescent with death from malignant lymphoma, histiocytic type (Reticulum cell sarcoma). Cancer (Philad.), 25, 206-211.

Jinich, H., Rojas, E., Webb, J. A., and Kelsey, J. D., Jr. (1968). Lymphoma presenting as malabsorption. Gastroenterology, 54, 421-425. 
Keele, K. D., and Pound, J. B. (1946). Sprue in India: clinical survey of 600 cases. Brit. med. J., 1, 77-81.

Kent, T. H. (1964). Malabsorption syndrome with malignant lymphoma. Arch. Path., 78, 97-103.

Klipstein, F. A., and Falaiye, J. M. (1969). Tropical sprue in expatriates from the tropics living in the continental United States. Medicine (Baltimore), 48, 475-491.

Lehmkuhl, H. (1927). Ein Fall von gleichmässigem diffusem Lymphosarkom des Dünndarms. Virchows. Arch. path. Anat., 264, 39-44.

Lindenbaum, J., Kent, T. H., and Sprinz, H. (1966). Malabsorption and jejunitis in American peace corps volunteers in Pakistan. Ann. intern. Med., 65, 1201-1209.

Loehry, C. A., and Creamer, B. (1966). Post-mortem study of smallintestinal mucosa. Brit. med. J., 1, 827-829.

Luzzatto, L., Usanga, E. A., and Reddy, S. (1969). Glucose-6-phosphate dehydrogenase deficient red cells: resistance to infection by malarial parasites. Science, 164, 839-842.

McGrath, J., O'Farrell, P. T., and Boland, S. J. (1940). Giardial steatorrhoea. Irish med. J., 802-816.

Mackie, F. P., and Fairley, N. H. (1929). The morbid anatomy of sprue. Indian J. med. Res., 16, 799-825.

Marcuse, P. M., and Stout, A. P. (1950). Primary lymphosarcoma of the small intestine. Cancer (Philad.), 3, 459-474.

Marshak, R. H., Wolf, B. S., and Eliasoph, J. (1961). The Roentgen findings in lymphosarcoma of the small intestine. Amer. J. Roentgenol., 86, 682-692.

Massachusetts General Hospital Case Record 43081 (1957). New Engl. J. Med., 256, 357-362.

Nasr, K., Haghighi, P., Bakhshandeh, K., and Haghshenas, M. (1970). Primary lymphoma of the upper small intestine. Gut, 11, 673678.

O'Conor, G. T. (1963). Significant aspects of childhood lymphoma in Africa. Cancer Res., 23, 1514-1518.

Page, A. R., Hansen, A. E., and Good, R. A. (1963) Occurrence of leukemia and lymphoma in patients with agammaglobulinemia. Blood, 21, 197-206.

Peterson, R. D. A., Cooper, M. D., and Good, R. A. (1965). The pathogenesis of immunologic deficiency diseases. Amer. J. Med., 38, 579-604.

Ramot, B., Shahin, N., and Bubis, J. J. (1965). Malabsorption syndrome in lymphoma of small intestine. A study of 13 cases. Israel J. med. Sci., 1, 221-226.

Rechnitzer, P. (1953). Three cases of small intestinal neoplasm. Gastroenterologia (Basel), 79, 343-345.

Ronaghy, H. A., Kohout, E., and Hadidi, N. (1970). Body height and chronic malnutrition in schoolchildren in Iran. Amer. J. clin. Nutr., 23, 1080-1084.

Rosecan, M., Trobaugh, F. E., Jr., and Danforth, W. H. (1955).
Agammaglobulinemia in the adult. Amer. J. Med., 19, 303313.

Rosenberg, S. A., Diamond, H. D., Jaslowitz, B., and Craver, L. F. (1961). Lymphosarcoma: a review of 1,269 cases. Medicine (Baltimore), 40, 31-85.

Salera, U., Coppolino, L., Cannata, D., and Serafini, N. A. (1960). Sindrome spruetica da reticulosarcoma delle linfoghiandole mesenteriche. Riforma med., 74, 1505-1513.

Salvesen, H. A. (1948). Symptomatic sprue due to reticulosarcomatosis of the small intestine and mesentery glands. Gastroenterologia (Basel), 73, 166-172.

Sanford, J. P., Favour, C. B., and Tribeman, M. S. (1954). Absence of serum gamma globulins in an adult. New Engl. J. Med., 250, 1027-1029.

Schlaeger, R. (1967). Malignant lymphoma. In Alimentary Tract Radiology, vol. II, pp. 680-688, edited by A. R. Margulies and H. J. Burheme. Mosby, St. Louis.

Scudamore, H. H. (1961). Observations on secondary malabsorption syndromes of intestinal origin. Ann. intern. Med., 55, 433-447.

Shreeve, D. R., Horrocks, P., and Mainwaring, A. R. (1968). Steatorrhoea and intra-abdominal lymphoma. Scand. J. Gastroent. $3,577-585$.

Siegmund, H. (1929). Einfache Entzündung des Darmrohres. In Henke Lubarsch. Handbuch der speziellen pathologischen Anatomie und Histologie. Vol. IV/3, pp. 272-286, edited by F. Henke and $O$. Lubarsch. Springer, Berlin.

Singleton, A. O., Jr., and Moore, R. M. (1949). Lymphosarcoma of the gastrointestinal tract. Texas Rep. biol. Med., 7, 33-46.

Skrimshire, J. F. P. (1955). Lymphoma of stomach and intestine. Quart. J. Med., 24, 203-214.

Sleisenger, M. H., Almy, T. P., and Barr, D. P. (1953). Sprue syndrome secondary to lymphoma of the small bowel. Amer. J. Med., 15, 666-674.

Thin, G. (1890). Psilosis (linguae et mucosae intestini). Brit. med. J., 1, 1358-1361.

Tonkin, R. D. (1963). Reticulosis of the small bowel as a late complication of idiopathic steatorrhoea. Proc. roy. Soc. Med., 56, 167-168.

Ullman, A., and Abeshouse, B. S. (1932). Lymphosarcoma of the small and large intestines. Ann. Surg., 95, 878-915.

Upshaw, C. B., Jr., and Pollard, H. M. (1957). The sprue syndrome associated with intraabdominal lymphoblastoma. Gastroenterology, 33, 104-112.

Wall, R. L., and Saslaw, S. (1955). Adult agammaglobulinemia. Arch. intern. Med., 95, 33-36.

Wethered, F. J. (1891). Psilosis or sprue. Trans. path. Soc. Lond., 42, 116-119.

Whitehead, R. (1968). Primary lymphadenopathy complicating idiopathic steatorrhoea. Gut, 9, 569-575. 